Int. J. Dev. Biol. 48: 1131-1140 (2004)

doi: $10.1387 / \mathrm{ijdb} .041913 \mathrm{ee}$

Original Article

\title{
Insulin-like growth factor (IGF) signalling is required for early dorso-anterior development of the zebrafish embryo
}

\author{
EDWARD EIVERS ${ }^{1}$, KARENA MㄷCRTHY ${ }^{1}$, CATHERINE GLYNN ${ }^{1}$, CATHERINE M. NOLAN ${ }^{2}$ and LUCY BYRNES ${ }^{*, 1}$ \\ ${ }^{1}$ Department of Biochemistry, National University of Ireland, Galway and ${ }^{2}$ Department of Zoology, University College Dublin, Ireland
}

\begin{abstract}
The insulin-like growth factor (IGF) signalling pathway has been highly conserved in animal evolution and, in mammals and Xenopus, plays a key role in embryonic growth and development, with the IGF-1 receptor (IGF-1R) being a crucial regulator of the signalling cascade. Here we report the first functional role for the IGF pathway in zebrafish. Expression of mRNA coding for a dominant negative IGF-1R resulted in embryos that were small in size compared to controls and had disrupted head and CNS development. At its most extreme, this phenotype was characterized by a complete loss of head and eye structures, an absence of notochord and the presence of abnormal somites. In contrast, up-regulation of IGF signalling following injection of IGF-1 mRNA, resulted in a greatly expanded development of anterior structures at the expense of trunk and tail. IGF-1R knockdown caused a significant decrease in the expression of Otx2, Rx3, FGF8, Pax6.2 and Ntl, while excess IGF signalling expanded Otx2 expression in presumptive forebrain tissue and widened the $\mathbf{N t l}$ expression domain in the developing notochord. The observation that IGF-1R knockdown reduced expression of two key organizer genes (chordin and goosecoid) suggests that IGF signalling plays a role in regulating zebrafish organizer activity. This is supported by the expression of IGF-1, IGF-2 and IGF-1R in shield-stage zebrafish embryos and the demonstration that IGF signalling influences expression of $B M P 2 b$, a gene that plays an important role in zebrafish pattern formation. Our data is consistent with a common pathway for integration of IGF, FGF8 and anti-BMPs in early vertebrate development.
\end{abstract}

KEY WORDS: zebrafish, IGF-1R, DN-IGF-1R, embryonic development, patterning

\section{Introduction}

The insulin-like growth factor (IGF) signalling system is highly conserved in vertebrates. The IGF family includes two secreted ligands, IGF-1 and IGF-2, which bind to and signal through the IGF-1 receptor (IGF-1R). The structurally related insulin molecule transduces its signal through its own receptor, the insulin receptor, although cross-reactivity with the IGF-1R may occur (Jones and Clemmons, 1995). Both the IGF-1R and the insulin receptor belong to the tyrosine kinase receptor superfamily and constitute heterotetrameric transmembrane proteins with two $\alpha$-chains and two $\beta$-chains linked by disulphide bonds. The extracellular region contains the ligand binding domain and the intracellular region contains the ligand-activated tyrosine kinase domain. Ligand binding triggers receptor auto-phosphorylation and initiates tyrosine kinase activity, which subsequently phosphorylates a host of intracellular substrates, including insulin receptor substrates (IRS-1-3) and Src homology/collagen proteins (Shc). This leads to the activation of two main signalling pathways, the Mitogenic Activated Protein Kinase (MAPK) and the Phosphatidylinositol-3 Kinase/Akt-1 (PI3K/Akt-1) pathways (Jones and Clemmons, 1995; Butler et al., 1998; Blume-Jensen and Hunter, 2001).

IGF-1R function is essential for normal embryonic development. Mice lacking the IGF-1R (Igf-1r-/-) are only $45 \%$ the weight of their wild-type littermates (Liu et al., 1993). These dwarfs invariably die at birth with generalised muscle hypoplasia, de-

\footnotetext{
Abbreviations used in this paper: BMP, bone morphogenetic protein; Chd, chordin; CI-MPR, cation-independent mannose 6-phosphate receptor; CNS, central nervous system; DN-IGF-1R, dominant negative IGF-1R; Gsc, goosecoid; hpf, hours post fertilisation; IGF, insulin-like growth factor; IGF1R, IGF-1 receptor; IGF-1R-MO, IGF-1R-morpholino; IGF-2R, IGF-type 2 receptor; IRS, insulin receptor substrates; MAPK, mitogenic activated protein kinase; PI3K, phosphatidylinositol-3 kinase; Shc, Src homology/collagen proteins.
}

\footnotetext{
*Address correspondence to: Dr. Lucy Byrnes. Department of Biochemistry, National University of Ireland, Galway, Ireland. Fax: +353-91-525-700. e-mail: lucy.byrnes@nuigalway.ie web: http://www.nuigalway.ie/faculties_departments/biochemistry/staff/byrnes/
} 
layed bone development and abnormal central nervous system (CNS) morphology. An identical phenotype to the $\lg f-1 r(-/-)$ mutant was found in $\lg f-1(-/-) \lg f-1 r(-/-)$ double mutant mice, demonstrating that the IGF-1R mediates all the effects of the IGF1 ligand during embryonic development (Liu et al., 1993; PowellBraxton et al., 1993). IGF-2 also binds to the IGF-1R, but Igf-1r(1-) Igf-2(p-) double knockouts had even more severe growth retardation than the $/ g f-1 r$ knockout, suggesting that IGF-2 also acts through another receptor, which was subsequently identified as the insulin receptor (Baker et al., 1993; Liu et al., 1993; Morrione et al., 1997). IGF-2 binds with high affinity to the IGFtype 2 receptor (also known as the cation-independent mannose 6-phosphate receptor) in mammals (IGF-2R/CI-MPR) (Tong et al., 1988; Grimme et al., 2000). The IGF-2R is a single-chain protein consisting of a large extracellular domain and a small cytoplasmic tail that lacks kinase activity (Ludwig et al., 1995) and there is no compelling evidence to suggest a role for the IGF-2R/ CI-MPR in transducing IGF-2 signals (Filson et al., 1993).

The knockout experiments in mice clearly demonstrated the importance of IGF-1R-mediated mitogenic activity during mammalian development. A novel role for the IGF signalling system has since been described: IGF signals are potent neural inducers and are both required and sufficient for head formation in the frog embryo (Xenopus laevis). Disruption of the endogenous IGF-1R by microinjection of a dominant negative IGF-1R (DN-IGF-1R)or an IGF-1R-morpholino (IGF-1R-MO) into Xenopus embryos blocked the formation of the head (Pera et al., 2001; RichardParpaillon et al., 2002). Overexpression of the IGF ligands, by microinjecting mRNA into the Xenopus embryo, induced overgrowth of forebrain tissue and promoted the formation of head structures, including ectopic eyes and cement glands (Pera et al., 2001). These overexpression studies also revealed that injection of IGFs into the prospective ventral side of the Xenopus embryo led to the formation of ectopic head-like structures containing brain, olfactory placodes and eyes. Following the initial findings that IGFs were potent neural inducers, Pera and co-workers demonstrated that IGF-2 favours neural induction in Xenopus embryos by inhibiting Bone Morphogenetic Protein (BMP) signalling (Pera et al., 2003). BMP receptors are serine-threonine protein kinases, which transduce their intracellular signals by phosphorylating Smad1 at its carboxy terminal, thus switching on

\section{TABLE 1}

\section{DN-IGF-1R MRNA INJECTION PHENOTYPES}

\begin{tabular}{lcccccc}
\hline $\begin{array}{l}\text { Injected } \\
\text { sample }^{\mathbf{a}}\end{array}$ & $\begin{array}{c}\text { Weak }^{\mathbf{b}} \\
(\mathbf{n})\end{array}$ & $\begin{array}{c}\text { Intermediate }^{\mathbf{c}} \\
(\mathbf{n})\end{array}$ & $\begin{array}{c}\text { Severe }^{\text {d }} \\
(\mathbf{n})\end{array}$ & $\begin{array}{c}\text { Unaffected } \\
(\mathbf{n})\end{array}$ & $\begin{array}{c}\text { Dead } \\
\text { embryos (n) }\end{array}$ & $\begin{array}{c}\text { Viable } \\
\text { embryos }^{\mathbf{e}}(\mathbf{n})\end{array}$ \\
$500 \mathrm{pg}$ & 35 & 1 & 0 & 74 & 8 & 110 \\
$1 \mathrm{ng}$ & 51 & 10 & 6 & 52 & 11 & 119 \\
$2 \mathrm{ng}$ & 56 & 16 & 17 & 13 & 12 & 102 \\
Phenol Red & 1 & 1 & 0 & 133 & 14 & 135
\end{tabular}

Note. The experiment was performed over three days. On each day approximately 40 embryos were injected with one of the indicated concentrations or with phenol red

a Amount of injected $D N-/ G F-1 R$ mRNA per embryo.

${ }^{b}$ Weak phenotype had reduced head, eyes and tail and a slight reduction in body size.

${ }^{c}$ Intermediate phenotype had loss of head and eyes and a reduction in body size.

d Severe phenotype embryos displayed a severely disrupted body pattern, lacking any distinguishable dorso-ventral features.

e Total numbers of embryos alive after $24 \mathrm{hpf}$.

$n$, numbers of embryos.
Smad1 activity and promoting the formation of ventral tissue. In contrast, IGF activated MAPK signalling can cause inhibition of Smad1 activity by phosphorylating the protein in the linker region. These findings suggest that neural induction in the Xenopus embryo is favoured by low Smad1 activity and high MAPK signalling (Pera et al., 2003).

A study in cultured cells indicates that IGF signalling pathways in zebrafish are similar to those in mammalian systems and that IGF-1 binds to the IGF-1R and activates the MAPK- and the PI3K pathways in the zebrafish ZF-4 cell line (Pozios et al., 2001). Limited information is available on IGF activity in zebrafish in vivo. Expression of zebrafish /GF-1 and IGF-2 mRNA is ubiquitous throughout the developing zebrafish embryo and at all stages of development studied, from 8 cell stage to 72 hours post fertilisation (hpf) (Maures et al., 2002). Expression was strongest in the anterior portion of the embryo, most notably in the eyes, brain tissue and other nervous tissues (Chen et al., 2001; Maures et al., 2002). In contrast to the presence of a single lgf-1r gene in mammals, two functional $/ g f-1 r$ genes ( $/ g f-1 r a$ and $/ g f-1 r b)$ are present in zebrafish (Ayaso et al., 2002; Maures et al., 2002). Phylogenetic analyses of protein and cDNA sequences group the zebrafish IGF-1Rs in the vertebrate IGF-1R clade, distinct from the insulin receptor or insulin-related receptor clades. IGF-1Ra and $/ G F-1 R b \mathrm{mRNAs}$ and proteins are expressed in overlapping spatial domains in vivo, but exhibit distinct temporal expression patterns in specific tissues and organs. Strong expression for both receptors was particularly notable in anterior neural tissue, especially in the developing brain and eyes at $24 \mathrm{hpf}$. To date however, no functional investigations of the IGF signalling system have been described in this organism.

To investigate if IGF-1R-mediated signalling is involved in growth and development during zebrafish embryogenesis, we performed loss-of-function and gain-of-function experiments. Loss of IGF-1R function was achieved by microinjection of $D N-/ G F-1 R$ mRNA into zebrafish embryos, while gain-of-function was achieved by overexpressing /GF-1 mRNA. Loss of IGF signalling resulted in small sized embryos and disrupted head and CNS development, with extreme phenotypes displaying a complete loss of head and eye structures, together with the absence of a notochord and abnormal somites. In contrast, overexpression of /GF1 resulted in dorsalised embryos with reduced tail and trunk tissue. These phenotypes, together with in situ analysis of gene expression in gastrula stage and segmentation period embryos, indicate that IGF signalling in zebrafish plays an important role in the early patterning of embryos in neural development and in embryonic growth. Our data provide direct evidence that the in vivo activities associated with this signalling system during mammalian and amphibian embryonic development are also present in more ancient vertebrates, indicating conservation of function from a common vertebrate ancestor.

\section{Results}

To investigate the potential role of the IGF signalling system during zebrafish embryonic development we first adopted a knockdown approach using a zebrafish DN-IGF-1R protein. This was achieved using a zebrafish IGF-1Ra 508/STOP construct encoding a receptor that lacks transmembrane and intracellular domains (DN-IGF-1R). The human version of this construct is 
A

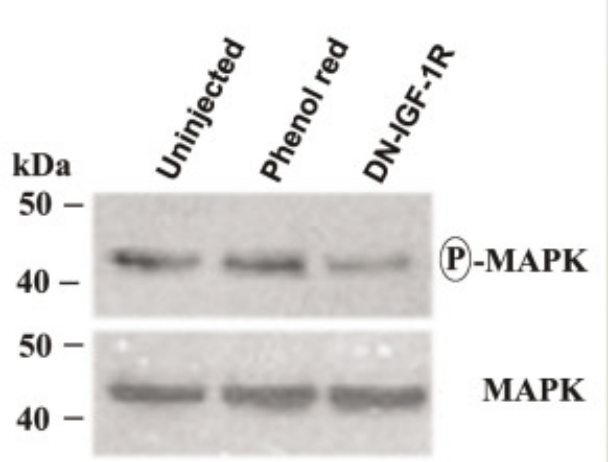

B

Control
C

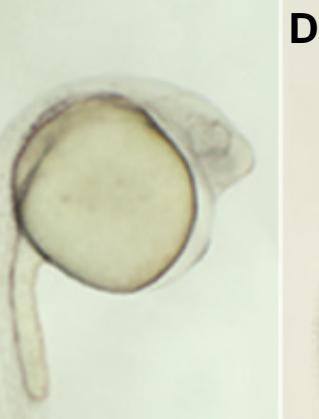

D

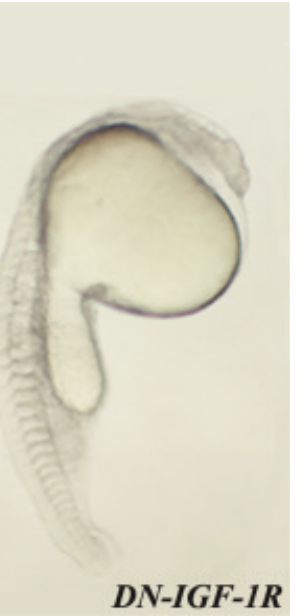

Fig. 1. Phenotypes of $\mathbf{D N}$-IGF-1R injected zebrafish embryos during the early pharyngula period (24 hpf). All embryos were injected at the $1-2$ cell stage with 2 ng DN-IGF-1R mRNA. (A) Western blot analysis showing phosphorylated MAPK at the late gastrula stage (80\% epiboly) in uninjected, phenol red injected and DN-IGF-1R mRNA injected zebrafish embryos; phosphorylated MAPK was reduced in DN-IGF-1R injected embryos compared to control zebrafish embryos. Total MAPK was detected as a loading control. (B) Lateral view of control embryo ( $n=135 / 135)$. (C) Lateral view of embryo injected with DN-IGF-1R mRNA. A reduction in the length of the anterior posterior axis is apparent $(n=77 / 102)$. (D) Injection of DN-IGF-1R mRNA resulted in abnormal somite morphology ( $n=37 / 102)$, in addition to a loss of head ( $n=17 / 102)$, eye structures $(n=38 / 102)$ and notochord (Lateral view).

secreted and inhibits ligand-induced activation of endogenous IGF-1Rs (D'Ambrosio et al., 1996), while the Xenopus version functions in vivo in a dominant negative capacity (Pera et al., 2001). We inserted a FLAG domain at the 3' end of the DN-/GF$1 R$ construct and following microinjection of its $m R N A$ into zebrafish embryos, the FLAG-tagged protein was detected by western blotting, confirming translation of DN-IGF-1R (data not shown).

\section{Inhibition of MAPK phosphorylation by DN-IGF-1R}

Following ligand-induced activation of IGF-1R, MAPK is one of the two main signalling cascades activated (Jones and Clemmons, 1995). To test the effectiveness of the zebrafish DN-IGF-1R in inhibiting intracellular signalling, we examined the phosphorylation status of endogenous MAPK in embryos that had been injected with $2 \mathrm{ng} D N-/ G F-1 R$ mRNA at the $1-2$ cell stage. The phosphorylation of p44/42 MAPK was examined using an antiphospho-MAPK-specific antibody, while an anti-MAPK antibody was used to assess the total level of MAPK in the embryos. At the $80 \%$ epiboly stage, phosphorylation of MAPK was down-regulated in $D N-/ G F-1 R$ injected embryos compared to controls (uninjected embryos or embryos injected with phenol red) (Fig. 1A). Total MAPK levels were similar in all the three groups of embryos. This reduction of MAPK phosphorylation indicates that the zebrafish DN-IGF-1R is an effective inhibitor of endogenous IGF-1R signalling.

\section{DN-IGF-1R activity results in loss of anterior structures and a reduction in body size}

A dose response assay was performed in which $D N-/ G F-1 R$ mRNA amounts of $500 \mathrm{pg}, 1 \mathrm{ng}$ and $2 \mathrm{ng}$ per embryo were injected into the yolk of zebrafish embryos at the 1-2 cell stage of development. Two experimental controls were used: uninjected embryos and phenol red injected embryos. Embryos were assessed at $24 \mathrm{hpf}$ by visual analysis using light microscopy. At this stage the zebrafish embryo is most evidently bilaterally organised, with a well-developed notochord and well-sculptured head, eyes and brain (Kimmel et al., 1995).

The phenotypes observed in $D N-/ G F-1 R$ injected embryos were divided into three distinct classes: weak, intermediate and severe (Table 1). The weak phenotypic class consisted of embryos displaying a reduction in the head, eyes and tail with the body being slightly reduced in size. The intermediate phenotypic class had embryos, which contained a loss of head and eye structures with a more extensive reduction in overall body size. The severe phenotype consisted of embryos with a severely disrupted body pattern, lacking any distinguishable dorso-ventral features (Fig. 1 C,D). Injection of $500 \mathrm{pg}$ of $D N-/ G F-1 R$ mRNA per embryo had little effect on overall development: the majority of embryos were unaffected, $32 \%$ had a weak phenotype and no embryos with intermediate or severe phenotypes were recorded. Doubling the amount of injected $D N-/ G F-1 R$ mRNA to $1 \mathrm{ng}$ per embryo resulted in the majority of embryos displaying either an unaffected or weak phenotype with a small number having intermediate or severe phenotypes. Microinjection of $2 \mathrm{ng} D N-/ G F-1 R$ mRNA per embryo resulted in $55 \%$ of embryos displaying the weak phenotype, with significant numbers displaying intermediate and severe phenotypes (16 and $17 \%$ respectively) (Table 1 , Fig. 1). The majority of the $2 \mathrm{ng} D N-/ G F-1 R$ mRNA injected embryos ( $75 \%$ of viable embryos) were reduced in body size. In addition, the embryos displaying intermediate and severe phenotypes had a complete loss of head structures and were also lacking a notochord and had swollen U-shaped somites. Of the phenol-red injected embryos $(n=135)$, only two had abnormal phenotypes (Table 1), similar to the frequency of abnormalities observed in non-injected embryos (data not shown). In summary, IGF-1R knockdown in zebrafish embryos results in a dosedependent loss of anterior structures together with a reduction in embryonic body size, while the absence of a notochord in some embryos suggests that activity of the organizer may have been impaired in these animals. 


\section{Control}

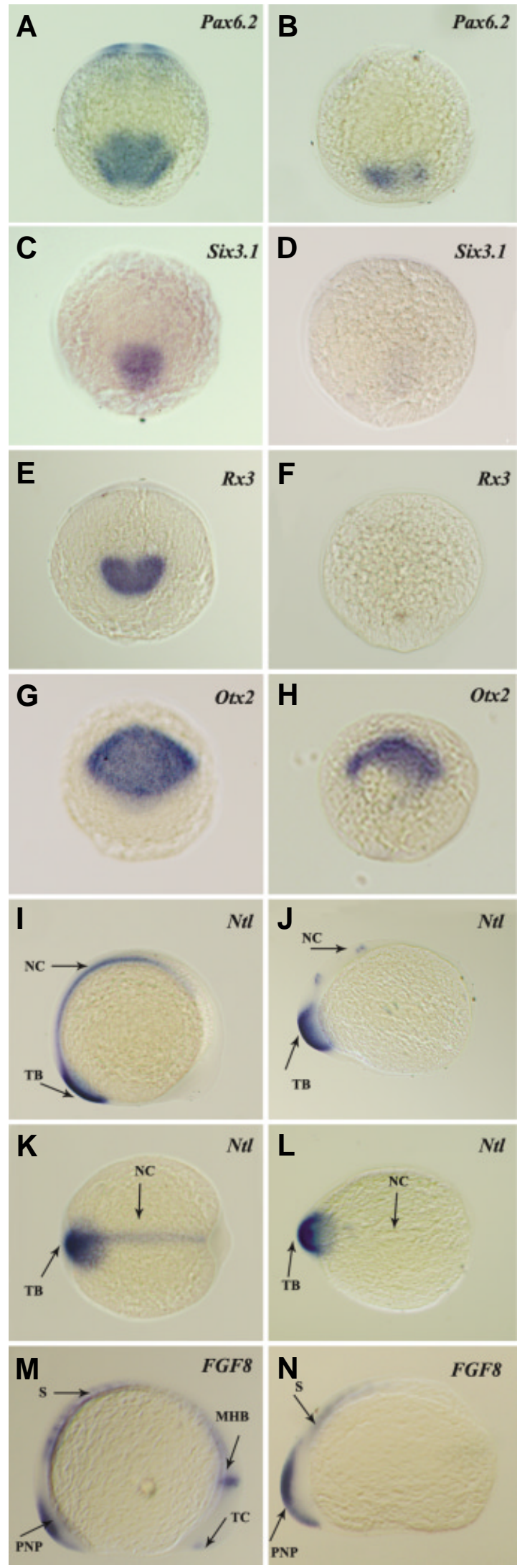

IGF-1R signalling is required for normal anterior and CNS development in zebrafish

To further characterise the phenotype of DN-IGF-1R expressing embryos, we examined the expression of a number of genes that are critical for normal neural development and for notochord and somite formation. We initially examined expression of Pax6.2, Six3.1, $R \times 3$ and Otx2 in $10 \mathrm{hpf}$ embryos. At $10 \mathrm{hpf}$, Pax6.2 expression is normally detected in the forebrain (eye field and lens placodes) and along the midline region (Nornes et al., 1998; Fig. 2A). A disrupted Pax6.2 expression pattern was detected in $D N$ IGF-1R injected embryos with partial loss of expression in the presumptive forebrain tissue and along the midline (Fig. 2B). Six3. 1, a homeobox gene, is first expressed in the involuting axial mesoderm and subsequently in the anterior neural plate from which the optic vesicles and forebrain develop (Seo et al., 1998; Fig. 2C). The expression pattern of this gene was either absent or severely reduced in the $D N-/ G F-1 R$ injected embryos (Fig. 2D). Expression of $R \times 3$, a retinal homeobox gene, is detected at $10 \mathrm{hpf}$ in the anterior-most neural plate which gives rise to the forebrain and retinal tissues (Chuang et al., 1999; Fig. 2E). 30\% of embryos injected with the $D N-/ G F-1 R$ mRNA $(\mathrm{n}=22 / 68)$ displayed a complete loss of $R \times 3$ expression (Fig. $2 \mathrm{~F})$ and a further $40 \%(\mathrm{n}=$ 29/68) had a partial loss of expression (data not shown). Otx2 expression is important in the early specification of the neuroectoderm (Mori et al., 1994; Simeone, 1998) and its expression is detected in the presumptive forebrain-midbrain at $10 \mathrm{hpf}$ (Mori et al., 1994; Fig. 2G). In DN-/GF-1Rinjected embryos, partial loss of Otx2 expression was detected in the most anterior expression domain (Fig. 2H). Our analysis of Pax6.2, Six3.1, Rx3 and Otx2 expression in $D N-/ G F-1 R$ injected embryos indicates that expression of genes involved in eye and forebrain development are dependent on IGF signalling.

Analysis of markers at $15 \mathrm{hpf}$ verified the loss of anterior tissue and also confirmed the involvement of IGF-1R in notochord formation. Expression of $\mathrm{Nt} /$ is essential for zebrafish notochord development and at $15 \mathrm{hpf}$ this gene is normally detected in the developing notochord and in the prospective mesodermal cells of

Fig. 2. Altered expression of marker genes along the anterior-posterior axis in DN-IGF-1R injected zebrafish embryos. (A) Control embryo showing normal Pax6.2 expression. (B) Reduction in Pax6.2 expression in the developing eye region and complete loss of Pax6.2 along the midline region of an embryo injected with DN-IGF-1R mRNA. (C) Control embryo showing normal expression of Six3.1. (D) Injection of DN-IGF-1R mRNA caused a reduction in Six3.1 expression in the anterior neural plate. (E) Control embryo showing normal $\mathrm{R} \times 3$ expression. (F) Loss of $\mathrm{R} \times 3$ expression in embryo injected with DN-IGF-1R mRNA. (G) Control embryo showing normal Otx2 expression. (H) Partial loss of Otx2 expression in embryo injected with DN-IGF-1R mRNA. (I) Lateral view and (K) dorsal view, of control embryo showing normal Ntl expression. (J) Lateral view and (L) dorsal view of embryo injected with DN-IGF-1R mRNA. An absence of $\mathrm{Ntl}$ expression is detected along the notochord, while $\mathrm{Ntl}$ expression is still present in the tail bud region. (M) Lateral view of control embryo showing normal FGF8 expression in embryo. (N) Lateral view of DN-IGF$1 \mathrm{R}$ injected embryo. An absence of FGF8 expression was detected in the anterior-most telencephalon region while expression was reduced in the midbrain-hindbrain boundary. Frequency of embryos with the indicated expression patterns was $A, 75 / 75 ; B$ 51/63; C, 64/64; D, 23/34; E, 53/53; F, 22/68; G, 56/56; H, 34/43; I,K, 38/38; J,L, 41/62; M, 80/80; N, 25/50. Abbreviations: $S$, somites; PNP, posterior neural plate; $M H B$, midbrainhindbrain boundary; TC, telencephalon; NC, notochord; TB, tail bud. 
the tail bud (Schulte-Merker et al., 1992; Fig. 2 I,K). In $D N-/ G F-1 R$ injected embryos, $N$ t/ expression was severely disrupted or absent with expression detected only in the most posterior tail bud region (Fig. $2 \mathrm{~J}, \mathrm{~L}$ ). FGF8 expression is critical for normal CNS development and at $15 \mathrm{hpf}$ is normally detected in the telencephaIon, midbrain-hindbrain boundary, developing somites and posterior neural plate (Fürthauer et al., 1997; Fig. 2M). In $D N-/ G F-1 R$ injected embryos, expression of $F G F 8$ is absent in the telencephalon and midbrain-hindbrain region, while expression in the posterior neural plate is unaffected (Fig. 2N).

\section{Overexpression of IGF-1 results in a dorsalised phenotype with an expansion of anterior tissues and reduction in trunk and posterior structures}

We next adopted a gain-of-function approach to analyse IGFmediated signalling by injecting /GF-1 mRNA into zebrafish embryos. Using a similar experimental design to that described for the $D N-/ G F-1 R$ injections, we performed a dose response assay with three /GF-1 amounts $(250 \mathrm{pg}, 375 \mathrm{pg}$ and $500 \mathrm{pg}$ mRNA per embryo). Injections were into a single blastomere, at the 1-4 cell stage of development and the experiment also
TABLE 2

\section{IGF-1 mRNA INJECTION PHENOTYPES}

\begin{tabular}{lcccccc}
$\begin{array}{l}\text { Injected } \\
\text { sample }^{\mathbf{a}}\end{array}$ & $\begin{array}{c}\text { Weak } \\
(\mathbf{n})\end{array}$ & $\begin{array}{c}\text { Intermediate } \\
(\mathbf{n})\end{array}$ & $\begin{array}{c}\text { Severe } \\
(\mathbf{n})\end{array}$ & $\begin{array}{c}\text { Normal } \\
\text { embryos (n) }\end{array}$ & $\begin{array}{c}\text { Dead } \\
\text { embryos (n) }\end{array}$ & $\begin{array}{c}\text { Viable } \\
\text { embryos }^{\mathbf{b}}(\mathbf{n})\end{array}$ \\
\hline $250 \mathrm{pg}$ & 13 & 0 & 0 & 93 & 10 & 106 \\
$375 \mathrm{pg}$ & 28 & 20 & 9 & 64 & 12 & 121 \\
$500 \mathrm{pg}$ & 33 & 30 & 28 & 24 & 18 & 115 \\
Phenol Red & 0 & 0 & 0 & 120 & 14 & 120
\end{tabular}

Note. Zebrafish embryos were injected into a single blastomere at the 1-4 cell stage. $n$, number of embryos.

a, amount of injected /GF-1 mRNA.

$\mathrm{b}$, total numbers of embryos alive after $24 \mathrm{hpf}$.

included (as controls) uninjected embryos and embryos injected with phenol red. When the /GF-1 injected embryos were examined at $24 \mathrm{hpf}$, a range of abnormalities was apparent along the anterior-posterior axis and embryos appeared dorsalised compared to control embryos (Fig. 3). The abnormal embryos were divided into three phenotypic classes: weak, intermediate and
Fig. 3. Phenotypes generated by overexpression of IGF-1 in zebrafish embryos. A range of phenotypes was recorded after injection of 500 pg IGF-1 mRNA. (A-D) Lateral views of embryos at 24 hpf; (E,F) dorsal views of embryos at 11-12 hpf, anterior to the right; (G-J) lateral views of embryos at 15 hpf; (K-L) dorsal views of embryos at 15 hpf. (A) Controlzebrafish embryo displaying normal phenotype. Normal tail length is delimited by arrows. (B) Weak phenotype is apparent in embryo injected with IGF-1 mRNA, shown as a small reduction in the tail region, delimited byarrows. (C) Intermediate phenotype in embryo injected with IGF-1 mRNA, represented by a shortened twisted tail with an apparently normal head. (D) Severe phenotype in embryo injected with IGF-1 mRNA, characterised by a head-like structure sitting on top of the yolk with deletion of both trunk and tail. (E) Control embryo displaying normal Otx2 expression. (F) Expansion of the Otx2 expression towards ventral domains in embryo injected with IGF-1 mRNA. (G) FGF8 expression in control embryo. (H) Increased FGF8 expression is detected in the telencephalon and midbrain/ hindbrain domains in IGF-1 injected embryos. Embryos also display a shortened anterior-posterior embryonic axis. (I,K) Ntl expression in control embryo. $(\mathrm{J}, \mathrm{L})$ Broader $\mathrm{Ntl}$ expression is detected in the notochord, while the anterior-posterior embryonic axis is shortened shown by the decrease in the length of $\mathrm{Ntl}$ expression. Numbers of embryos displaying the described phenotypes was $A, 120 / 120 ; B, 33 / 115 ; C, 30 / 115 ; D, 28 / 115$. Frequency of embryos with the indicated expression patterns was $E, 30 / 30 ; F, 36 / 62 ; G, 80 / 80 ; H, 33 / 49 ; I, K, 40 / 40 ; J, L, 50 / 65$. Abbreviations: S, somites; PNP, posterior neural plate; MHB, midbrain-hindbrain boundary; TC, telencephalon; NC, notochord; TB, tail bud.
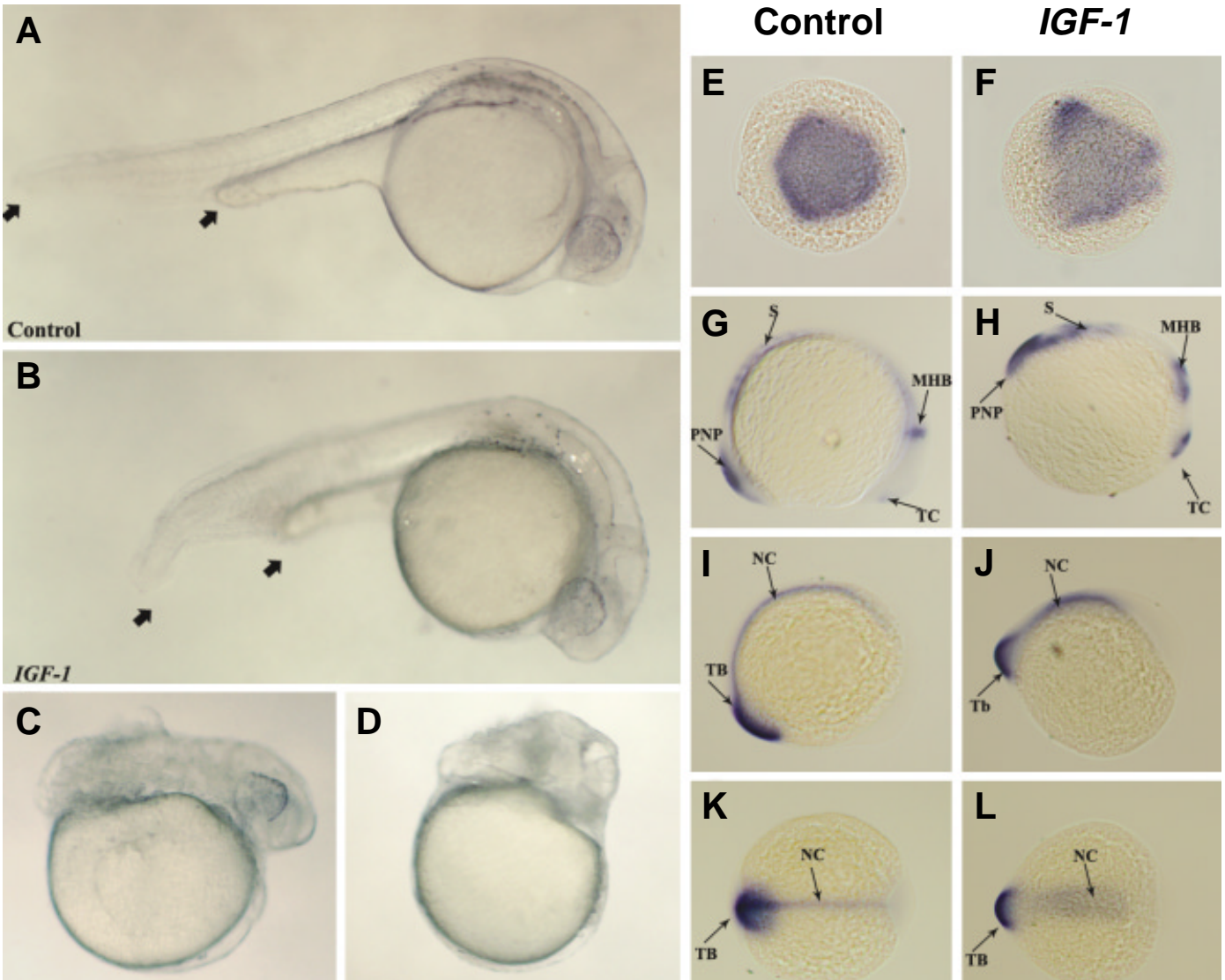

엉
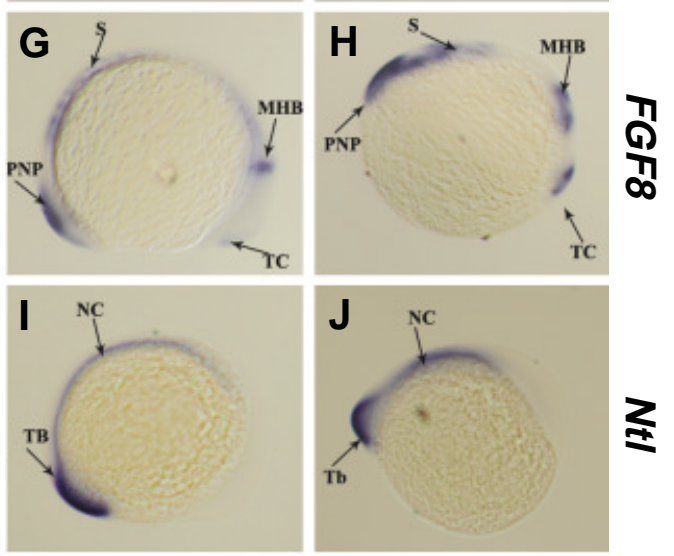

IGF-I
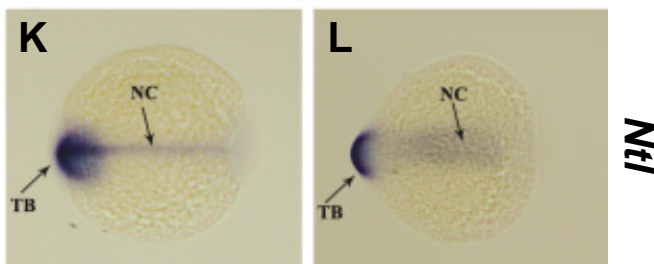

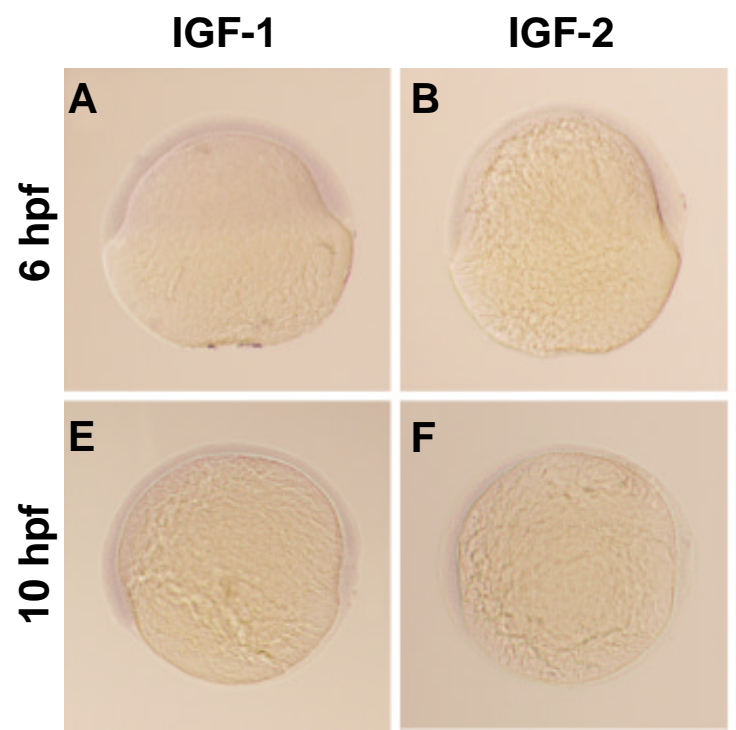

G
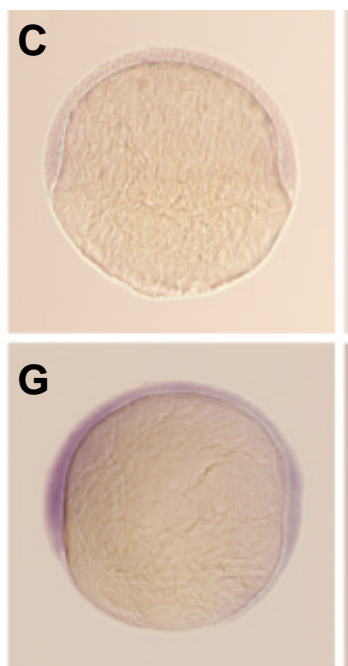

IGF-1Rb

\section{D}

H

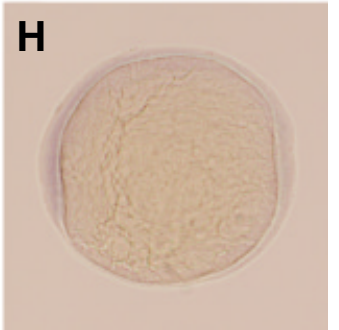

Fig. 4. Localisation of IGFtranscripts during mid to late gastrulation in zebrafish embryos. (A-D) Expression of the IGF-1, IGF-2, IGF-1Ra and IGF-1Rb mRNAs at 6 hpf, expression is detected in a weak diffuse pattern throughout the embryo. (E-H) Expression of IGF-1, IGF-2, IGF-1 Ra and IGF-1Rb mRNAs at 10 hpf. IGF-1 and IGF2 mRNAs are expressed in a weak diffuse pattern, while IGF-1Ra and IGF-1Rb are detected more strongly in the anterior portion of the embryo. The number of embryos displaying the indicated expression patterns were $A, 30 /$ $30 ; B, 24 / 24 ; C, 38 / 38 ; D, 27 / 27 ; E, 34 / 34 ; F, 32 / 32 ; G, 31 / 31 ; H, 31 / 31$.

severe (Table 2). The weak phenotype consisted of a slight shortening of the tail, with no disruption to the anterior of the embryo (Fig. 3B). The intermediate phenotype consisted of a shortened and twisted tail, with a slightly enlarged anterior region (Fig. 3C). The severe phenotype comprised of strongly dorsalised embryos displaying a loss of the tail, a severe reduction in the trunk region and a greatly enlarged anterior structure (Fig. 3D). At the lowest /GF-1 concentration ( 250 pg/embryo), some embryos exhibited the weak phenotype, while the majority had no visible abnormalities. Embryos injected with $375 \mathrm{pg} / G F-1 \mathrm{mRNA}$ had a higher frequency of the weak phenotype, with intermediate and severe phenotypes also recorded. At the highest mRNA dose (500 pg/embryo), over $75 \%$ of embryos had abnormal phenotypes and these were divided almost equally over the three phenotypic classes (Table 2). No abnormal phenotypes were observed in uninjected embryos (data not shown) or in embryos injected with phenol red (Table 2). Over-expression of /GF-1 therefore, in contrast to $D N-/ G F-1 R$ expression, results in the development of anterior structures at the expense of more posterior structures.

The dorsalised phenotype of /GF-1 injected embryos was confirmed by in situ hybridization analysis of the expression of genes that are critical for anterior neural (Otx2, FGF8) and notochord (Nt) development. Comparison of /GF-1 injected embryos with control embryos at 11-12 hpf showed that Otx2 expression was expanded along the dorsal-ventral axis (Fig. 3 E,F). FGF8 expression was also enhanced in the telencephalon region of /GF-1 injected embryos at $15 \mathrm{hpf}$ compared to controls, with stronger expression detected in the midbrain-hindbrain boundary (Fig. $3 \mathrm{G}, \mathrm{H}$ ). In addition, posterior expression of FGF8in /GF1 injected embryos shifted more anteriorly (Fig. $3 \mathrm{H})$. Analysis of $\mathrm{Nt} /$ expression at $15 \mathrm{hpf}$ in /GF-1 injected embryos (Fig. $3 \mathrm{~J}, \mathrm{~L}$ ) showed that expression was shortened along the anterior-posteExpression of the four genes was detected weakly and ubiquitously in the dorsal and ventral regions of the zebrafish embryo at $6 \mathrm{hpf}$ (Fig. 4 A-D). Expression of /GF-1 and /GF-2 was also detected weakly and ubiquitously at $10 \mathrm{hpf}$ (Fig. $4 \mathrm{E}, \mathrm{F})$. However, expression of /GF-1Raand /GF-1Rbwas increased in the anterior region of the embryo at this time (Fig. $4 \mathrm{G}, \mathrm{H}$ ). Thus mRNAs for IGF ligands and receptors are expressed throughout the zebrafish embryo during gastrulation, consistent with their involvement in patterning processes.

\section{IGF signalling is essential for patterning in the early zebrafish embryo}

In vertebrates, the body plan is established early in development by a group of cells known as the organizer (in teleost fish, the shield). To see if manipulation of IGF signalling influences expression of zebrafish genes that mediate organizer function, we examined the expression patterns of two genes essential for dorso-ventral patterning and for forebrain development, Chordin (Chd) and Goosecoid (GsC). Chordin is an essential component of the organizer and in normal shield stage embryos (6 hpf), Chd expression is detected in the organizer and surrounding tissue (Schulte-Merker et al., 1997; Fig. 5A). Injection of the DN-/GF-1R mRNA caused a significant reduction in the expression of $C h d$, although it did not completely abolish it (Fig. 5B). In contrast, embryos injected with /GF-1 mRNA had a slight expansion of $C h d$ expression during the shield stage $(n=21 / 30)$ (data not shown). Gsc expression is also a component of the zebrafish organizer and in shield stage embryos, is normally detected in the organizer region as a narrow stripe along the anterior-posterior axis (Thisse et al., 1994; Fig. 5C). Injection of $D N-/ G F-1 R$ mRNA resulted in a reduction in the Gscexpression domain (Fig. 5D). The finding that IGF-1R activity regulates expression of key organizer genes in the gastrula embryo, strongly implicates a requirement for IGF signal- 
ling in organizer function in the zebrafish and thus in the normal patterning of the embryo along the anterior-posterior and dorsalventral axes.

A conserved feature of vertebrate organizers is that they secrete antagonists of several classes of growth factors (Niehrs, 2004). For example, molecules such as Chordin, Noggin and Follistatin promote the formation of neural tissue in Xenopus by antagonizing BMP activity (Sasai et al., 1995). Two of our observations suggested that IGF-1R signalling might regulate this activity. Firstly, injection of $D N-/ G F-1 R$ mRNA decreased $C h d$ expression in zebrafish and secondly, the dorsalised phenotype of embryos overexpressing /GF-1 has features in common with swirlembryos that are mutated in the BMP2bgene (Kishimoto et al., 1997). We therefore examined expression of $B M P 2 b$ in embryos with altered IGF signalling. In $D N-/ G F-1 R$ injected embryos, $B M P 2 b$ expression is expanded on the dorsal side of the embryo at $6 \mathrm{hpf}$ and the gene is expressed throughout the embryo (Fig. 5 E,F). In contrast, when embryos were injected with /GF-1 mRNA, BMP2b expression was more restricted to the ventral region compared to control embryos (Fig. $5 \mathrm{G}, \mathrm{H}$ ).

\section{Discussion}

This is the first report of a functional role for the IGF signalling system during zebrafish embryonic development. Disruption of endogenous IGF-1Rs, by microinjecting $D N-/ G F-1 R$ mRNA, resulted in a loss of head and eye structures and an absence of notochord. In addition, a decrease in embryonic body size was found, resulting in embryos being proportionate dwarfs when compared to controls. The importance of IGF signalling in development of anterior zebrafish structures was also demonstrated by overexpression of one of the receptor's ligands. Excess /GF-1 dorsalised the embryos, with the most extremely affected embryos showing an expansion of the forebrain region and a reduction in trunk and tail tissues. The phenotype of both groups of embryos suggests a novel role for IGF signalling in regulating organizer function. The fact that the two /GFigands and receptors are expressed throughout early development, in particular at the shield stage, is consistent with such a role, as was the observation that $D N-/ G F-1 R$ expression down-regulated expression of two key mediators of organizer action, Chdand GsC.

The dorsalised phenotype of embryos over-expressing /GF-1 resembled, in some characteristics, the phenotype of zebrafish swir/mutants and of embryos overexpressing FGF8 (Fürthauer et al., 1997; Kishimoto et al., 1997). The swir/phenotype results from mutation of the $B M P 2 b$ gene and is characterized by expanded dorsal structures, such as notochord and loss of ventral tissue. In /GF-1 overexpressing embryos, the notochord is shortened along the A-P axis and expanded laterally, with a complete loss of posterior and ventral tissue in extreme cases. The phenotype of FGF8 overexpressing zebrafish embryos consisted of a reduced tail (mild phenotype) or loss of both trunk and tail (severe phenotype) (Fürthauer et al., 1997). These similarities suggest that the IGF-, FGF8- and BMP-signalling pathways might function in a common pathway to regulate anterior development in zebrafish. In Xenopus, such co-ordination is known to occur and IGF and FGF8 participate in a common pathway of inhibiting BMP signalling. Activation of Xenopus MAPK by IGF-2 and/or FGF8 can phosphorylate Smad1, an important effector of BMP signalling, in
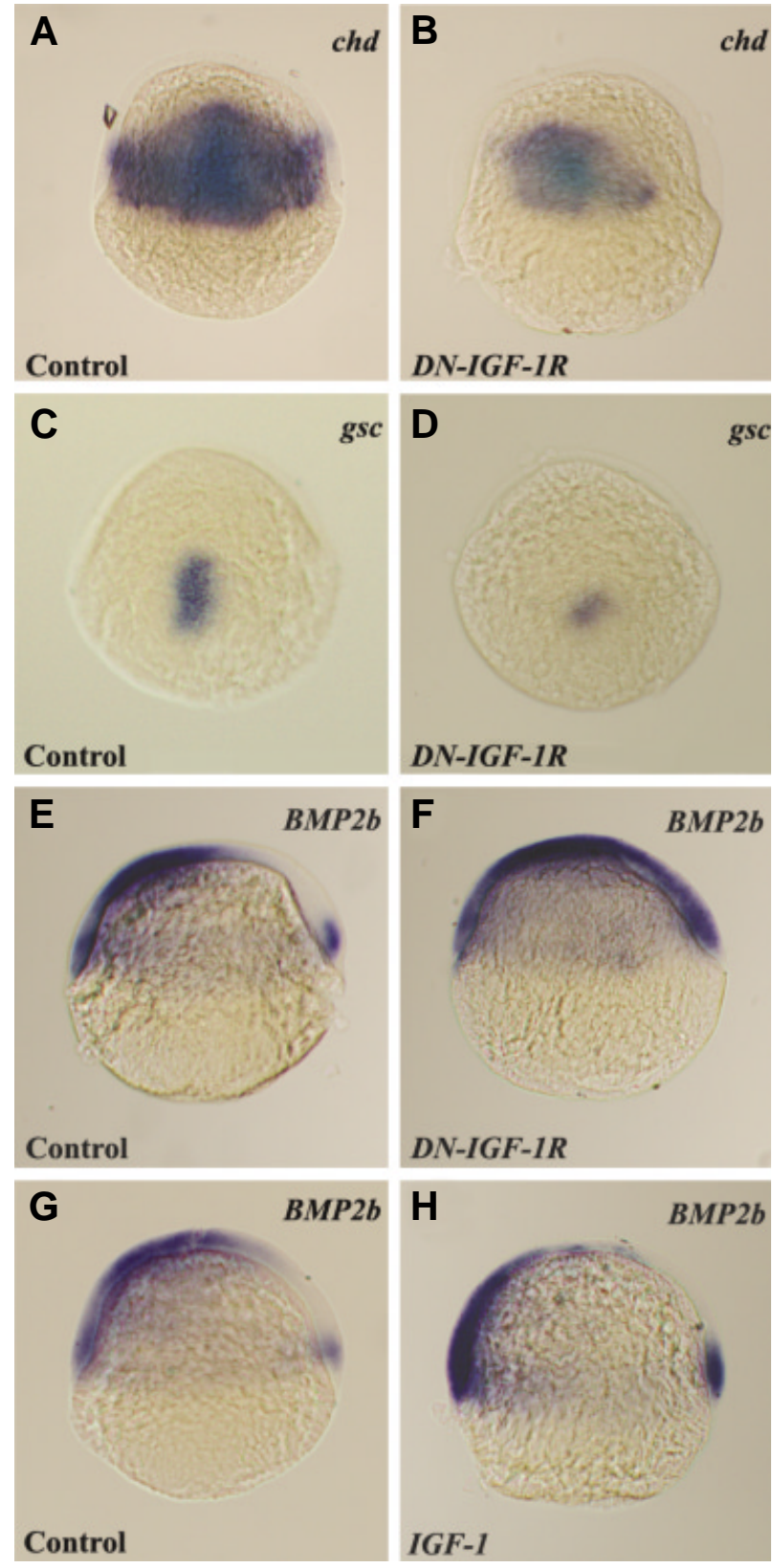

Fig. 5. IGFs and dorso-ventral gene expression at the gastrula stage. All embryos are shown as lateral views. (A) Control embryo showing normal Chd expression. (B) DN-IGF-1R injected embryo with reduced expression of Chd. (C) Control embryo showing normal expression of Gsc. (D) Reduction in the expression of Gsc in embryo injected with the DN-IGF-1R mRNA. $(\mathbf{E}, \mathbf{G})$ Expression pattern for BMP2b in control zebrafish embryo. (F) Increased BMP2b expression in embryo injected with DN-IGF-1R. (H) Decreased expression of BMP2b in embryo injected with IGF-1 mRNA. The frequency of embryos with the described expression patterns was: $A, 36 /$ $36 ; B, 45 / 62 ; C, 81 / 81 ; D, 63 / 107 ; E, 89 / 89 ; F, 35 / 54 ; G, 89 / 89 ; H, 21 / 30$

the central linker region (Pera et al., 2003). This phosphorylation inhibits Smad1 activity and promotes neural tissue formation. Our results show that expression of the $D N$-/GF-1Ror overexpression of $/ G F-1$ resulted in increased or decreased detection of $B M P 2 b$ mRNA levels respectively. Also $D N$-/GF-1R or /GF-1 expression 
resulted in decreased or increased expression of $C$ hd, which codes for an antagonist of BMP signalling. Therefore, our experimental data and the phenotypes of FGF8 and swir/mutants, are consistent with the coordination of these signaling pathways in zebrafish development.

IGF-1R knockdown in zebrafish embryos has also revealed novel roles for this signalling system in the formation of the midbrain-hindbrain boundary and of notochord. Injection of the $D N-/ G F-1 R$ caused a reduction or loss of $F G F 8$ in the midbrainhindbrain boundary and of $N t /$ in the developing notochord. When IGF-1 was overexpressed in the zebrafish embryo, an expansion of FGF8and Nt/was detected in the midbrain-hindbrain boundary and notochord respectively. These results clearly demonstrate an essential role for IGF signalling in these regions. Further analysis is needed to fully understand how IGF function contributes to the development of these tissues.

A role for the IGF-1R in regulating vertebrate body size was first indicated by the dwarf phenotype of mice deficient in IGF-1R and/ or IGF-1 (Liu et al., 1993; Powell-Braxton et al., 1993) and more recently, a similar role for the IGF-1R was extended to humans (Abuzzahab et al., 2003). In the latter study, two human patients with intrauterine growth retardation and poor postnatal growth were found to have mutations in the /GF-1Rgene. The first patient was a compound heterozygote for two point mutations in exon 2 of the $/ G F-1 R$ gene. Fibroblasts cultured from this patient had decreased IGF-1R function compared to control fibroblasts. The second patient was heterozygous for a nonsense point mutation in exon 2, with the arginine at position 59 converted to a stop codon. Exon 2 is the first $/ G F-1 R$ exon to encode a substantial portion of the mature receptor and therefore no viable receptor is expected as a result of this mutant allele. The number of IGF-1Rs per fibroblast was lower in this patient than in controls (Abuzzahab et al., 2003). Interestingly, growth retardation was not reported in the IGF-1 $R$ knockdown studies in Xenopus (Pera et al., 2001; Richard-Parpaillon et al., 2002).

The phenotype of the mouse IGF-1R knockouts, with the decrease in overall body size being the most obvious feature, had suggested that the IGF signalling system plays a somewhat limited role in regulating cell fate and differentiation in vivo (Liu et al., 1993; Powell-Braxton et al., 1993). However, the relatively normal cell differentiation in IGF-1R deficient mice contrasts with the results observed in Xenopus (Pera et al., 2001; RichardParpaillon et al., 2002) and now in zebrafish. Our demonstration of IGF-1R involvement in neural development in zebrafish suggests that this may represent an ancestral function of the receptor and is not a derived feature of amphibians. It is possible that the activity of the IGF signalling cascade in anterior head development has been retained in both Xenopus and zebrafish, but has become redundant in mice or masked by other factors during evolution. Given the complexity of the mammalian IGF system, with the existence of several ligands, receptors and binding proteins and its involvement in cellular processes as diverse as proliferation, differentiation, survival, motility and apoptosis, it is likely that it includes a high level of functional redundancy.

A further explanation for the phenotypic differences between IGF-1R-deficient zebrafish and Xenopus embryos, compared to the mouse IGF-1R knockouts, may reside in the different experimental approaches used to inhibit receptor function. In the case of the zebrafish and Xenopus knockdown experiments (this study, Pera et al., 2001), the secreted DN-IGF-1R protein may interact with both IGF-1 and IGF-2 ligands and with insulin and may interfere with signalling through the IGF-1R and insulin receptors. Thus the dominant negative approach might be predicted to produce a more severe phenotype than would be expected from the more specific receptor inactivation carried out in the mouse. In keeping with this, genetic experiments in the mouse have shown that some of the activity of IGF-2 is mediated through the insulin receptor. Mice deficient in both the insulin receptor and IGF-1R, have a more severe phenotype than mice deficient in only one receptor (D'Ercole et al., 1996; Morrione et al., 1997; Efstratiadis, 1998). On the other hand, Richard-Parpaillon et al. (2002) used antisense morpholinos to knockdown IGF-1R function in Xenopusand the phenotype they observed was similar to that seen by Pera et al. (2001) with the DN-IGF-1R protein. The morpholino approach should be more selective than the dominant negative experiments and it will be interesting to see if knockdown of zebrafish IGF-1Rs by this approach produces a less severe phenotype.

In conclusion, our study describing IGF-mediated growth and differentiation defects in a single species, suggests that Danio rerio is a unique model organism for experiments designed to understand the evolution of the IGF signalling pathway and how coordination of its diverse activities is achieved in vivo.

\section{Materials and Methods}

\section{Zebrafish maintenance}

AB-wild type zebrafish (Danio rerio) were raised and maintained as described in Westerfield, 1995. The fish were fed three times daily. Embryos were obtained by natural crosses.

\section{Plasmid constructs}

PCR amplification using 72 hour zebrafish cDNA was used to generate a secreted DN-IGF-1R cDNA. This encodes a truncated version of the zebrafish IGF-1Ra (AF400275) with a stop codon downstream of the arginine at position 508 of the extracellular domain. The primers were designed with an EcoRI (D1, 5'-AAA GAA TTC ATG AGA TCT GGA ACA GCG AG-3') and an Xbal (D2, 5'-AAA TCT AGA TCA TCG CTC CCA AGT GAG CTT-3') restriction site added to their 5' ends (underlined). The PCR fragment was subcloned into the EcoRI and Xbal sites in the pCS2+ expression vector. The $D N-/ G F-1 R$ flag-tagged construct was generated by carrying out $\mathrm{PCR}$ amplification on the $D N-/ G F-1 R$ plasmid using primers D1 and D3 (5'-GTT CTA GAT CAC TTG TCA TCG TCG TCC TTG TAG TCT CGC TCC CAA GTG-3'). The D3 primer was designed based on the D2 primer with modifications, a flag-tagged nucleotide sequence (bold) was added before the stop codon. To prepare the zebrafish /GF-1 (AF314545) expression vector the complete open reading frame for its CDNA was PCR amplified and subcloned into Clal and Xbal sites of pCS2+. The primers used were I1F, 5'-AAAATCGATATGTCTAGCGGTCATTTCTTC-3' with a Clal restriction site (underlined) and I1R, 5'-AAA TCT AGA CTA CAT GCG ATA GTT TCT G-3' containing a Xbal restriction site (underlined).

\section{Whole mount in situ hybridisation}

The localization of mRNA transcripts was determined using wholemount in situ hybridisation with digoxigenin-labelled riboprobes. Templates were transcribed in vitro using T7 or SP6 RNA polymerases (Roche) and riboprobes were purified using Quick Spin Columns (Roche) and resuspended in nuclease-free water. Embryos were prepared and processed for whole-mount in situ hybridisation as described previously (Hauptmann and Gerster, 1994; Brabazon et al., 2002). For colorimetric detection of alkaline phosphatase activity, BM-Purple AP-Substrate 
(Roche) was used. Visualisation and photography was performed using a Nikon Eclipse E600 microscope and DXM1200F digital camera.

\section{mRNA microinjection}

To prepare sense mRNA, $D N-/ G F-1 R$ and /GF-1 pCS2+ constructs were linearised with Notl and transcribed with SP6 polymerase using mMessage mMachine kit (Ambion). RNA was diluted in $5 \mathrm{mg} / \mathrm{ml}$ phenol red, $0.2 \mathrm{M} \mathrm{KCL}$ (2:1 dilution) prior to microinjection. Using a Narishige IM-300 microinjector $2 \mathrm{nl}$ of $D N-/ G F-1 R \mathrm{RNA}$ was injected into the yolk beneath the blastomeres at the 1-2 cell stage embryos. For /GF-1 RNA experiments, embryos were injected with $0.5 \mathrm{nl}$ of solution into a single blastomere at the 1-4 cell stage embryos.

\section{Protein extraction and Western blotting}

Embryos were injected with either phenol red/0.2 $\mathrm{M} \mathrm{KCl,} D N-/ G F-1 R$ mRNA (2 ng per embryo) or were uninjected at the 1-2 cell stage (55 embryos were used for each). Embryos were maintained to the late gastrula stage ( $80 \%$ epiboly) and carefully dechorionated and deyolked. Whole embryo extracts were then washed twice in $1 \mathrm{X}$ PBS, spun for 2 minutes at $8000 \mathrm{rpm}$ at $4^{\circ} \mathrm{C}$ and the supernatant was removed. Whole embryo pellets were snap-frozen in liquid nitrogen. Pellets were thawed on ice and $15 \mu \mathrm{l}$ of lysis buffer ( $400 \mathrm{mM} \mathrm{NaCl}, 20 \mathrm{mM}$ Tris pH 8.0, 20\% Glycerol, 2 mM DTT, Protease Inhibitor Cocktail [0.2 mM AEBSF, 1 mM EDTA, $130 \mu \mathrm{M}$ bestatin, $14 \mu \mathrm{M}$ E- $64,1 \mu \mathrm{M}$ leupeptin and $0.3 \mu \mathrm{M}$ aprotinin]) was added per thawed pellet. Samples were homogenised using a $100 \mu \mathrm{l}$ glass homogenizer. The samples were freeze-thawed 3 times in liquid nitrogen and an ice-water bath to release the proteins. The samples were then spun at $14000 \mathrm{rpm}$ for $15 \mathrm{~min}$ at $4^{\circ} \mathrm{C}$. Supernatants were transferred to fresh tubes. Protein concentration was measured using Bradford reagent. Equal aliquots of protein $(25 \mu \mathrm{g})$ were separated by $10 \%$ SDS-PAGE and immunoblotted onto nitrocellulose membrane. Western blots were performed using primary antibodies against mouse anti-phospho-MAPK (1:333, Cell Signalling) and rabbit anti-MAPK (1:500, Cell Signalling) and incubated with the secondary antibodies mouse peroxidase conjugated (1:2000, Sigma) and rabbit peroxidase conjugated ( $1: 3000$, Sigma). The membrane was washed and bound antibodies were visualised using Super Signal West Pico (Pierce).

\section{Acknowledgements}

We thank Andres Fjose, Terje Johansen, Milan Jamrich, Valerie MillerBertaglio, Dave Turner, Eric Weinberg and Len Zon for gifts of DNA plasmids; Maura Grealy for experimental planning and data analysis, Eva Denise Martin and Carolin Balduf for technical assistance and Ronan Bree, Carlos Brown, David Greenberg, James Kim, Hojoon Lee, Ashley Mays, Shaun O'Boyle, Bruno Reversade and Lise Zakin for critical comments on the manuscript. This work was supported by Enterprise Ireland (SC/02/ 448), IRCSET Embark (KMCC) and the NUI, Galway Millennium Fund.

\section{References}

ABUZZAHAB, M. J., SCHNEIDER, A., GODDARD, A., GRIGORESCU, F., LAUTIER, C., KELLER, E., KIESS, W., KLAMMT, J., KRATZSCH, J., OSGOOD, D., PFAFFLE, R., RAILE, K., SEIDEL, B., SMITH, R. J. and CHERNAUSEK, S. D. (2003). /GF-1 receptor mutations resulting in intrauterine and postnatal growth retardation. N. Engl. J. Med. 349: 2211-2222.

AYASO, E., NOLAN, C. M. and BYRNES, L. (2002). Zebrafish insulin-like growth factor-I receptor: molecular cloning and developmental expression. Mol. Cell Endocrinol. 191: 137-148.

BAKER, J., LIU, J. P., ROBERTSON, E. J. and EFSTRATIADIS, A. (1993). Role of insulin-like growth factors in embryonic and postnatal growth. Cel/75: 73-82.

BLUME-JENSEN, P. and HUNTER, T. (2001). Oncogenic kinase signalling. Nature 411: 355-365.

BRABAZON, E. D., BREE, R. T., CARTON, M. W., GREALY, M. and BYRNES, L. (2002). Cyclin-dependent kinase 8 is expressed both maternally and zygotically during zebrafish embryo development. Biochim. Biophys. Acta. 1576: 203-208.
BUTLER, A. A., YAKAR, S., GEWOLB, I. H., KARAS, M., OKUBO, Y. and LEROITH, D. (1998). Insulin-like growth factor-I receptor signal transduction: at the interface between physiology and cell biology. Comp. Biochem. Physiol. B. Biochem. Mol. Biol. 121: 19-26.

CHEN M.H., LIN G., GONG H., WENG C., CHANG C. and WU J. (2001). The characterization of prepro-insulin-like growth factor-1 Ea-2 expression and insulin-like growth factor-1 genes (devoid $81 \mathrm{bp}$ ) in the zebrafish (Danio rerio). Gene 268: 67-75

CHUANG, J. C., MATHERS, P. H. and RAYMOND, P. A. (1999). Expression of three $\mathrm{Rx}$ homeobox genes in embryonic and adult zebrafish. Mech. Dev. 84: 195-198.

D'AMBrosio, C., FERBER, A., RESNICOFF, M. and BASERGA, R. (1996). A soluble insulin-like growth factor I receptor that induces apoptosis of tumor cells in vivo and inhibits tumorigenesis. Cancer Res. 56: 4013-4020.

D'ERCOLE, A. J., YE, P., CALIKOGLU, A. S. and GUTIERREZ-OSPINA, G. (1996). The role of the insulin-like growth factors in the central nervous system. Mol. Neurobiol. 13: 227-255.

EFSTRATIADIS, A. (1998). Genetics of mouse growth. Int. J. Dev. Biol. 42: 955-976.

FILSON, A. J., LOUVI, A., EFSTRATIADIS, A. and ROBERTSON, E. J. (1993). Rescue of the T-associated maternal effect in mice carrying null mutations in Igf2 and Igf2r, two reciprocally imprinted genes. Development 118: 731-736.

FURTHAUER, M., THISSE, C. and THISSE, B. (1997). A role for FGF-8 in the dorsoventral patterning of the zebrafish gastrula. Development 124: 4253 4264.

GRIMME, S., HONING, S., VON FIGURA, K. and SCHMIDT, B. (2000). Endocytosis of insulin-like growth factor II by a mini-receptor based on repeat 11 of the mannose 6-phosphate/insulin-like growth factor II receptor. J. Biol. Chem. 275: 33697-33703.

HAUPTMANN, G. and GERSTER, T. (1994). Two-color whole-mount in situ hybridization to vertebrate and Drosophila embryos. Trends Genet. 10: 266.

JONES, J. I. and CLEMMONS, D. R. (1995). Insulin-like growth factors and their binding proteins: biological actions. Endocr. Rev. 16: 3-34.

KIMMEL, C. B., BALLARD, W. W., KIMMEL, S. R., ULLMANN, B. and SCHILLING, T. F. (1995). Stages of embryonic development of the zebrafish. Dev. Dyn. 203: 253-310.

KISHIMOTO, Y., LEE, K. H., ZON, L., HAMMERSCHMIDT, M. and SCHULTEMERKER, S. (1997). The molecular nature of zebrafish swirl: BMP2 function is essential during early dorsoventral patterning. Development 124: 4457-4466.

LIU, J. P., BAKER, J., PERKINS, A. S., ROBERTSON, E. J. and EFSTRATIADIS, A. (1993). Mice carrying null mutations of the genes encoding insulin-like growth factor I (Igf-1) and type 1 IGF receptor (Igf1r). Cel/75: 59-72.

LUDWIG, T., LE BORGNE, R. and HOFLACK, B. (1995). Roles for mannose-6phosphate receptors in lysosomal enzyme sorting, /GF- 1 l binding and clathrincoat assembly. Trends Cell Biol. 5: 202-206.

MAURES, T., CHAN, S. J., XU, B., SUN, H., DING, J. and DUAN, C. (2002). Structural, biochemical and expression analysis of two distinct insulin-like growth factor I receptors and their ligands in zebrafish. Endocrinology 143: 1858-1871.

MORI, H., MIYAZAKI, Y., MORITA, T., NITTA, H. and MISHINA, M. (1994). Different spatio-temporal expressions of three otx homeoprotein transcripts during zebrafish embryogenesis. Brain Res. Mol. Brain Res. 27: 221-231.

MORRIONE, A., VALENTINIS, B., XU, S. Q., YUMET, G., LOUVI, A., EFSTRATIADIS, A. and BASERGA, R. (1997). Insulin-like growth factor II stimulates cell proliferation through the insulin receptor. Proc. Natl. Acad. Sci. US A 94: 3777-3782.

NIEHRS C. (2004). Regionally specific induction by the Spemann-Mangold organizer. Nat. Rev. Genet. 6: 425-434.

NORNES, S., CLARKSON, M., MIKKOLA, I., PEDERSEN, M., BARDSLEY, A., MARTINEZ, J. P., KRAUSS, S. and JOHANSEN, T. (1998). Zebrafish contains two pax6 genes involved in eye development. Mech. Dev. 77: 185-196.

PERA, E. M., WESSELY, O., LI, S. Y. and DE ROBERTIS, E. M. (2001). Neural and head induction by insulin-like growth factor signals. Dev. Cell1: 655-665.

PERA, E. M., IKEDA, A., EIVERS, E. and DE ROBERTIS, E. M. (2003). Integration of IGF, FGF and anti-BMP signals via Smad1 phosphorylation in neural induction. Genes Dev. 17: 3023-3028. 
POWELL-BRAXTON, L., HOLLINGSHEAD, P., WARBURTON, C., DOWD, M., PITTS-MEEK, S., DALTON, D., GILLETT, N. and STEWART, T. A. (1993). /GF1 is required for normal embryonic growth in mice. Genes Dev. 7: 2609-2617.

POZIOS, K. C., DING, J., DEGGER, B., UPTON, Z. and DUAN, C. (2001). IGFs stimulate zebrafish cell proliferation by activating MAP kinase and PI3-kinasesignalling pathways. Am. J. Physiol. Regul. Integr. Comp. Physiol. 280: R12301239.

RICHARD-PARPAILLON, L., HELIGON, C., CHESNEL, F., BOUJARD, D. and PHILPOTT, A. (2002). The IGF pathway regulates head formation by inhibiting Wnt signalling in Xenopus. Dev. Biol. 244: 407-417.

SASAI, Y., LU, B., STEINBEISSER, H. and DE ROBERTIS, EM. (1995). Regulation of neural induction by the Chd and Bmp-4 antagonistic patterning signals in Xenopus. Nature 376: 333-336.

SCHULTE-MERKER, S., HO, R. K., HERRMANN, B. G. and NUSSLEIN-VOLHARD, C. (1992). The protein product of the zebrafish homologue of the mouse T gene is expressed in nuclei of the germ ring and the notochord of the early embryo. Development 116: 1021-1032.

SCHULTE-MERKER, S., LEE, K. J., MCMAHON, A. P. and HAMMERSCHMIDT, M. (1997). The zebrafish organizer requires chordino. Nature 387: 862-863.
SEO, H. C., DRIVENES, O., ELLINGSEN, S. and FJOSE, A. (1998). Expression of two zebrafish homologues of the murine Six3 gene demarcates the initial eye primordia. Mech. Dev. 73: 45-57.

SIMEONE, A. (1998). Otx1 and Otx2 in the development and evolution of the mammalian brain. EMBO J. 17: 6790-6798.

THISSE, C., THISSE, B., HALPERN, M. E. and POSTLETHWAIT, J. H. (1994). Goosecoid expression in neurectoderm and mesendoderm is disrupted in zebrafish cyclops gastrulas. Dev. Biol. 164: 420-429.

TONG, P. Y., TOLLEFSEN, S. E. and KORNFELD, S. (1988). The cation-independent mannose 6-phosphate receptor binds insulin-like growth factor II. J. Biol. Chem. 263: 2585-2588.

WESTERFIELD, M. (1995). The zebrafish book. University of Oregon Press.

Received: July 2004

Reviewed by Referees: August 2004

Modified by Authors and Accepted for Publication: October 2004 Edited by: Edward M. De Robertis 